\title{
Animais como vilões EPIDÊmicos
}

Diego Breno VILELA*

Framing Animals as Epidemic Villains integra uma série de publicações intitulada Medicine and Biomedical Sciences in Modern History ${ }^{155}$, idealizada pelo Professor John Pickstone (1944-2014) ${ }^{156}$. Possui como principal objetivo promover debates em torno dos impactos das ciências biomédicas no mundo contemporâneo e suas conexões com as estruturas econômicas, políticas e sociais - um esforço interdisciplinar de aproximação entre estudos nas áreas de medicina, ciências e tecnologias. $\mathrm{O}$ volume em questão foi editado e organizado pelo antropólogo Christos Lynteris (2019) ${ }^{157}$ (University of St Andrews-UK), sendo composto por nove capítulos (incluindo introdução e posfácio). Fruto da pesquisa de autores de diversos países e áreas do conhecimento, os capítulos retratam o surgimento e as transformações de quadros epidemiológicos e saúde pública, de doenças causadas por vetores não humanos em várias partes do mundo.

Em "Introduction: infectious animals and epidemic blame", Lynteris aponta que várias das epidemias ao longo do século XXI, tais como de Zika, SARS, gripe aviária ou ebola, têm em comum o fato de serem doenças transmitidas por vetores não humanos. Isto transformou determinadas classes de insetos/animais em verdadeiros "vilões epidêmicos". Esse enquadramento passa pelo reconhecimento da capacidade de uma dada espécie de propagar e/ou ser um hospedeiro de doenças para seres humanos. Mais do que uma introdução restrita a apresentar capítulos, Lynteris desenvolve importantes

\footnotetext{
* UEPB - Universidade Estadual da Paraíba. Centro de Ciências Humanas e Exatas. Departamento de Letras. Monteiro - PB - Brasil. 58500-000. brenolvilela@gmail.com. https://orcid.org/0000-0002-97208582.

155 Mais informações em: PALGRAVE Macmillan. Disponível em: https://www.palgrave.com/gp/series/15183. Acesso em: 04 nov. 2020.

156 Importante historiador da ciência e responsável por difundir uma área integrada de conhecimento: HSTM (História da Ciência, Tecnologia e Medicina).

157 Lynteris também é autor/editor de livros com temáticas semelhantes, por exemplo, Ethnographic Plague: configuring disease on the chinese-russian frontier (2016) e, junto com outros autores, Histories of Post-Mortem Contagion: infectious corpses and contested burials (2017); Plague and the City (2018); The Anthropology of Epidemics (2019).
} 
reflexões oferecendo ao leitor um bom panorama para sua imersão na temática geral do livro.

O segundo capítulo é assinado pela historiadora Karen Sayer e intitula-se "Vermin Landscapes: Suffolk, England, shaped by plague, rat and flea (1906-1920)". A autora toma como ponto de partida aquele que foi considerado o último surto de "peste pneumônica" da Inglaterra, ocorrido na cidade de Suffolk e adjacências, entre os anos de 1906 a 1920. Sayer está particularmente interessada nos fatores políticos e sociais de tal surto, bem como na intricada trama que enredou formuladores de políticas sanitárias, cientistas, profissionais de saúde e a imprensa da época. Uma das contribuições mais importantes do capítulo é a identificação da maneira pela qual as noções de classe, localidade e colonialidade balizaram a construção narrativa da doença e as medidas de saúde pública para sua contenção.

No capítulo III o antropólogo Christos Lynteris trata do caso das marmotas siberianas e como passaram a ser encaradas como "vilãs epidêmicas". Parte deste percurso está associado à descoberta de que os longos períodos de hibernação em tocas subterrâneas (outubro a abril), ampliavam a capacidade das marmotas preservarem, e, posteriormente, transportarem a bactéria Yersinia pestis, contribuindo para a persistência da doença na região. Lynteris põe em relevo o processo por meio do qual as marmotas e suas tocas emergiram como objetos de preocupação epidemiológica, enfatizando os métodos visuais utilizados para retratar, interrogar e pontuar as tocas desses animais como reservatórios da peste. $\mathrm{O}$ trabalho do autor constitui um ótimo exemplo para refletirmos sobre a construção de narrativas e controversas científicas, bem como a persistência de doenças em um determinado ambiente, mesmo sem haver grandes proximidades entre humanos e os vetores da doença. Também ganha destaque aqui a abordagem visual das epidemias (fotografia epidêmica), que permitem captar nuances que muitas vezes escapam aos textos escritos (KECK; KELLY; LYNTERIS, 2019).

O quarto capítulo é de autoria da antropóloga Deborah Nadal, que já no primeiro parágrafo de "To Kill or not to Kill: negotiating life, death, and one health in the context of dog-mediated rabies control in colonial and independent India", apresenta dados alarmantes: um terço das mortes humanas causadas por raiva no mundo ocorre na Índia (algo em torno de 20 mil pessoas por ano). Desta vez, os grandes "vilões epidêmicos" são os cães, portadores mais comuns do vírus da raiva. Nadal se debruça na longa história dos cães como propagadores da raiva na Índia, notando que o entendimento a respeito da zoonose - principalmente no período colonial - estava fortemente relacionado ao modo de classificar os cães: "cães sem dono", "vadios" ou "párias", eram aqueles que representavam perigo para a colônia, como também os maiores alvos, até o 
ano de 2001, das políticas de abate em massa para conter a doença ${ }^{158159}$. No entanto, isto não ocorreu sem conflitos. As relações entre cães-pessoas-doença se tornaram ainda mais complexas com o surgimento de grupos em defesa dos animais, que reivindicavam, ao invés do abate, a vacinação como solução para que humanos e cães se mantivessem saudáveis. Para a própria autora, a solução para o controle da raiva passa pelo reconhecimento de que os cães são tão vítimas da doença quanto os humanos. No entanto, em países como a Índia, onde os investimentos e o acesso à saúde são precários, "cuidar de cães" soa para parte da população como "não cuidar de humanos". Vacinálos e esterilizá-los, pode ser entendido como desperdício de tempo, recursos e dinheiro. Não por um acaso, surgiram grupos organizados favoráveis à eliminação dos cães, tais como Stray Dog Free Movement e o People for the Elimination of Stray Dogs in Maharashtra. Esses são apenas alguns dos elementos que atravessam esse cenário complexo etnografado por Nadal, repleto de conflitos e que envolve o entrelaçamento de elementos como colonialismo, hierarquia, cães, humanos, raiva e uma tensa relação "interespecífica".

Vetor de doenças como malária, dengue, febre amarela e filariose, mosquitos de diversos tipos e espécies são considerados em muitos contextos os maiores "vilões epidêmicos" para a humanidade. Neste livro, temos três capítulos dedicados a eles (V, VI e VIII).

Em “Tiger Mosquitoes from Ross to Gates”, Maurits Bastiaan Meerwijk faz um apanhado de pontos focais da história, onde os mosquitos foram representados como "vilões epidêmicos" no domínio público, em especial, como espécie "predatória", e, por vezes, dotados de "intencionalidade". O autor examina filmes, peças publicitárias, discursos científicos, médicos, governamentais e midiáticos que foram fundamentais nesse processo. Ganha destaque o uso de uma linguagem militar ou mesmo de guerra, para descrever a ameaça patogênica dos mosquitos e os meios para controlar sua presença "ameaçadora". Uma das grandes imagens nesse sentido é a do "mosquito tigre" (com pernas listradas), que reforça qualidades "predatórias" das espécies Aedes aegypti e Aedes albopictus. Considerando tais representações um tanto reducionistas, o autor aponta que, nas "estratégias de combate" por ele analisadas, toda a "culpa" recaiu nos

\footnotetext{
${ }^{158}$ A adoção de uma política de controle de matança em massa de animais não ocorreu apenas na Índia. Foi praticada amplamente em vários países, inclusive no Brasil. Em Recife-PE a chamada "carrocinha" exerceu a mesma política de captura e morte, levando os animais de rua para serem abatidos em centros de zoonoses até o final da década de 2000.

${ }^{159}$ Com o tempo, tais práticas se tornaram incompatíveis com a crescente sensibilidade em torno desses animais, que deixaram de ser vistos apenas como vetores de doença e se inserindo na esfera dos afetos (BAPSTELA; ABONÍZIO, 2017).
} 
mosquitos, que nada mais são do que vetores, isto quando portam algum vírus. Proceder desta forma simplifica e desconsidera a complexidade das verdadeiras causas das doenças infecciosas, que envolve forças culturais, econômicas e a própria relação da humanidade com o meio ambiente.

O segundo artigo no qual mosquitos figuram como protagonista é de autoria da antropóloga Luísa Reis-Castro e do historiador Gabriel Lopes. Em "A Vector in the (Re)Making: a history of Aedes aegypti as mosquitoes that transmit diseases in Brazil", os autores examinam o percurso histórico do mosquito do tipo Aedes Aegypti no Brasil, em três momentos epidêmicos distintos: febre amarela, dengue e Zika. Situados em diferentes contextos políticos e sociais da história do Brasil, os três distintos vírus moldaram o tipo de "vilão epidêmico" em que o mosquito se tornou. Mais do que isso: transformou sobremaneira os significados epidemiológicos e políticos decorrentes das interações "vírus-mosquito-humano". Durante a febre amarela (início do século XX), onde o vírus foi mais letal para a população de imigrantes europeus (brancos) recémchegados ao Brasil, eliminar o vírus, neste caso, o mosquito, tornou-se uma questão de "avanço civilizacional". No caso da dengue (a partir de 1986), a ausência de ações estatais efetivas para o seu enfrentamento desencadeou na população mais afetada pela doença uma série de reivindicações como direito a saúde, maior atenção e presença do Estado nas regiões mais vulneráveis, em suma, justiça social. Por fim, no contexto da Zika (a partir do final de 2015) ganhou relevância o entrelaçamento da doença, seus efeitos para as mulheres grávidas e seus filhos, com o debate em torno de pautas como direitos reprodutivos e ao aborto.

Encerrando as publicações sobre mosquitos, o oitavo capítulo, intitulado "Zika Outbreak in Brazil: in times of political and scientific uncertainties mosquitoes can be stronger than a country", Matta, Nogueira, Rabello e Silva analisam como a política de combate à epidemia do Zika vírus no Brasil assumiu um caráter de guerra declarada ao seu vetor primário, tornando o Aedes aegypti um vilão epidêmico global. No decorrer do capítulo, os autores demonstram a cada tópico, como essa "estrutura de guerra" criada para combater o mosquito, entrelaçou-se com discursos e interesses científicos, de Estado, da indústria de biotecnologia e com o próprio contexto de instabilidade política brasileira que resultou no impeachment da Presidente Dilma Rousseff.

O sétimo capítulo é de autoria da antropóloga médica Séverine Thys e tem como pano de fundo o surto de Ebola ocorrido em quatro distritos do sudoeste da República da Guiné (Guiné-Conacri, África), no ano de 2014. Além de apresentar taxas de mortalidade maiores quando comparada a outras regiões do país, chamou atenção da pesquisadora diversos episódios de resistência ou mesmo hostilidade à adoção das medidas oficiais para controle da doença. Diante deste quadro, Thys apresenta a 
hipótese de que parte considerável dessas atitudes estão relacionadas com as divergências entre "modelos explicativos" (KLEINMAN, 1980) para a origem e cadeia de transmissão do Ebola: de um lado, o "modelo biomédico", e de outro, as próprias versões locais para o surgimento da doença. Refletir sobre esses modelos e contrastálos constitui o objetivo principal da autora. Talvez este seja o artigo que menos concentra atenção nos chamados "vilões epidêmicos", dando mais ênfase às interpretações e significados da doença. No entanto, mantem-se alinhado à proposta do livro, demonstrando ao longo de todo o trabalho o caráter multidimensional da crise do Ebola na República da Guiné.

O livro é encerrado com o capítulo "Postscript: epidemic villains and the ecologies of nuisance", assinado pelo antropólogo francês Frédéric Keck. Nele, o autor recupera pontos centrais do que foi apresentado, afirmando que é possível traçar uma "geografia da culpa" das doenças epidêmicas transmitidas por animais não humanos.

Em conjunto, os capítulos de Framing Animals as Epidemic Villains - Histories of Non-Human Disease Vectors oferecem um panorama que reforça a necessidade de se examinar o entrelaçamento entre questões epidemiológicas e condicionantes históricos, sociais e culturais. Em tempos de pandemia global, em que muitas vezes a discussão em torno da doença se limita a estatísticas e debates técnicos, ou resvala em maniqueísmos simplistas do tipo economia x saúde pública, torna-se crucial a divulgação de esforços multidisciplinares como o que é realizado neste livro. Nesse cenário, o papel das Ciências Sociais é fundamental, no sentido de promover uma abordagem qualitativa e aprofundada desses fenômenos (SEGATA, 2020).

Se hoje parece óbvio que alguns animais são vetores, propagadores ou hospedeiros de patógenos que podem causar doenças aos seres humanos, foi apenas na virada do século XIX, com o desenvolvimento dos estudos bacteriológicos e da microbiologia, que eles começaram a ser enquadrados como "vilões", tornando-se protagonistas de uma série de "dramas epidêmicos". Como nos adverte Frédéric Keck em seu capítulo, os "vilões" também podem ser definidos como aqueles que desempenham um papel importante para o desenrolar de uma dada trama ou história. No caso em questão, os efeitos do enquadramento dos animais como "vilões epidêmicos" foram significativos. Não apenas reordenou as estruturas simbólicas, as associações entre humanos-animais e o modo de pensar a respeito de algumas espécies, como passou a ser parte constituinte da epidemiologia moderna, da saúde pública e do próprio gerenciamento estatal - expondo as fraquezas dos nossos sistemas de controle e vigilância de doenças (KECK; KELLY; LYNTERIS, 2019).

Uma das principais contribuições de Framing Animals as Epidemic Villains Histories of Non-Human Disease Vectors, é evidenciar processos que tornaram certos 
animais "vilões" e agentes epidêmicos globais, ao passo em que demonstra que eles estão enredados em contextos locais de significação. Lançada sobre o momento atual, a reflexão indica que os efeitos de uma epidemia, mesmo de caráter global, a exemplo da COVID-19, não são sentidos e experimentados da mesma forma, em todos os lugares. Questões que envolvem gênero, classe, raça ou geração são cruciais na forma como uma dada doença é experienciada. Em outras palavras, vírus, doenças, epidemias e seus efeitos, devem ser pensados sempre de forma situada (SEGATA, 2020), como "paisagens ou panoramas" da pandemia (APPADURAI,1999).

\section{REFERÊNCIAS}

APPADURAI, Arjun. Disjunção e diferença na economia cultural global. In:

FEATHERSTONE, Mike (Org.). Cultura global: nacionalismo, globalização e modernidade. Petrópolis: Vozes, 1999. p.311-328.

BAPTISTELLA, Eveline; ABONÍZIO, Juliana. O peso dos animais nas urnas: uma reflexão sobre o papel dos animais na política contemporânea. Revista Brasileira de Ciência Política. 2017, n.22, p.329-372.

ENGELMANN, Lukas; HENDERSON, John; LYNTERIS, Christos (Ed.). Plague and the City. Routledge, 2018.

KECK, Frédéric; KELLY, Ann H.; LYNTERIS, Christos. Introduction: the anthropology of epidemics. In: KELLY, Ann H.; KECK, Frédéric; LYNTERIS, Christos. The anthropology of epidemics. London: Routledge, col. Routledge Studies in Health and Medical Anthropology, 2019, p.1-23.

KELLY, Ann H., KECK, Frédéric; LYNTERIS, Christos (dir.). The Anthropology of Epidemics. London: Routledge, col. Routledge Studies in Health and Medical Anthropology, 2019.

KLEINMAN, Arthur. Patients andHealers in theContext of Culture. An Exploration of the Borderland Between Anthropology, Medicine and Psychiatry. Berkeley, CA: University of California Press, 1980.

LYNTERIS, Christos. Framing Animals as Epidemic Villains - Histories of Non-Human Disease Vectors. Medicine and Biomedical Sciences in Modern History. Palgrave Macmillan UK, 2019.

LYNTERIS, Christos. Ethnographic Plague: configuring disease on the chinese-russian frontier. Palgrave Macmillan UK, 2016. 
LYNTERIS, Christos; EVANS, Nicholas (Eds.). Histories of Post-Mortem Contagion: infectious corpses and contested burials. Palgrave Macmillan, 2017.

SEGATA, Jean. Covid-19: escalas da pandemia e escalas da antropologia. Boletim n.2, Cientistas Sociais e o Corona Vírus. Disponível em: http://anpocs.org/index.php/publicacoessp-2056165036/boletim-cientistas-sociais/2307-boletim-n-1-cientistas-sociais-o-o-coronavirus2. Acesso em: 20 jun.2020.

Recebido em 30/07/2020.

Aprovado em 07/09/2020. 